\title{
Regioselective carbon-carbon bond formation of 5,5,5-trifluoro-1-phenylpent-3-en-1-yne
}

\author{
Motoki Naka, Tomoko Kawasaki-Takasuka and Takashi Yamazaki ${ }^{*}$
}

\author{
Full Research Paper \\ Address: \\ Division of Applied Chemistry, Graduate School of Engineering, \\ Tokyo University of Agriculture and Technology, 2-24-16, Nakamachi, \\ Koganei 184-8588, Japan \\ Email: \\ Takashi Yamazaki* - tyamazak@cc.tuat.ac.jp \\ * Corresponding author \\ Keywords: \\ additives; computation; $\mathrm{Li} \cdots \mathrm{F}$ chelation; deprotonation; \\ electron-withdrawing effect; organo-fluorine
}

Beilstein J. Org. Chem. 2013, 9, 2182-2188.

doi:10.3762/bjoc. 9.256

Received: 10 August 2013

Accepted: 08 October 2013

Published: 23 October 2013

This article is part of the Thematic Series "Organo-fluorine chemistry III".

Guest Editor: D. O'Hagan

(C) 2013 Naka et al; licensee Beilstein-Institut.

License and terms: see end of document.

\begin{abstract}
The regioselective carbon-carbon bond formation was studied using 5,5,5-trifluoro-1-phenylpent-3-en-1-yne as a model substrate, and predominant acceptance of electrophiles $\beta$ to a $\mathrm{CF}_{3}$ group as well as a deuterium trap experiment of the lithiated species led to the conclusion that the obtained regioselectivity is kinetically determined for the reactions with electrophiles, under equilibration of the possible two anionic species.
\end{abstract}

\section{Introduction}

We have previously reported [1] the interesting behavior of $(E)$ 1-chloro-3,3,3-trifluoropropene ((E)-1) [2-4] towards MeLi, where the proportion of two possible products, propargylic alcohols $\mathbf{2}$ and allylic alcohols $\mathbf{3}$, was proved to be significantly dependent on the equivalents of MeLi used. Thus, as shown in Scheme 1, under the action of up to 1.6 equiv of MeLi, 2 was obtained as a sole product probably by initial $\mathrm{H}^{\mathrm{b}}$ abstraction from $(E)-\mathbf{1}$ and the resultant Int-1 was stabilized by the energetically favorable 5 -membered intramolecular $\mathrm{Li} \cdots \mathrm{F}$ chelation [5]. This intermediate Int-1 experienced Fritsch-ButtenbergWiechell (FBW) rearrangement [6,7] to give 3,3,3-trifluoropropyne, and Int-2 derived from this alkyne eventually captured appropriate aldehydes to afford $\mathrm{CF}_{3}$-containing propargylic alcohols 2 [8-12]. Alternatively, stereospecific and exclusive construction of the corresponding allylic alcohols $\mathbf{3}$ was attained by utilization of greater than 1.7 equiv of MeLi where the stabilized intermediate Int-3 formed by complexation of Int-1 with MeLi might play an important role. It turned out that the isomeric (Z)-1 as a substrate furnished only $\mathbf{2}$ [13] even by the addition of 1.7 equiv of MeLi, presumably as a result of regioselective deprotonation of $\mathrm{H}^{\mathrm{a}}$, followed by smooth elimination $[14,15]$ of the trans-disposed chlorine atom. However, it is also likely that the anionic intermediate produced after $\mathrm{H}^{\mathrm{b}}$ abstraction would prefer the reaction course to 2 by way of FBW rearrangement because of its lower stability than Int-1 with loss of the possibility for $\mathrm{Li} \cdots \mathrm{F}$ chelation. 


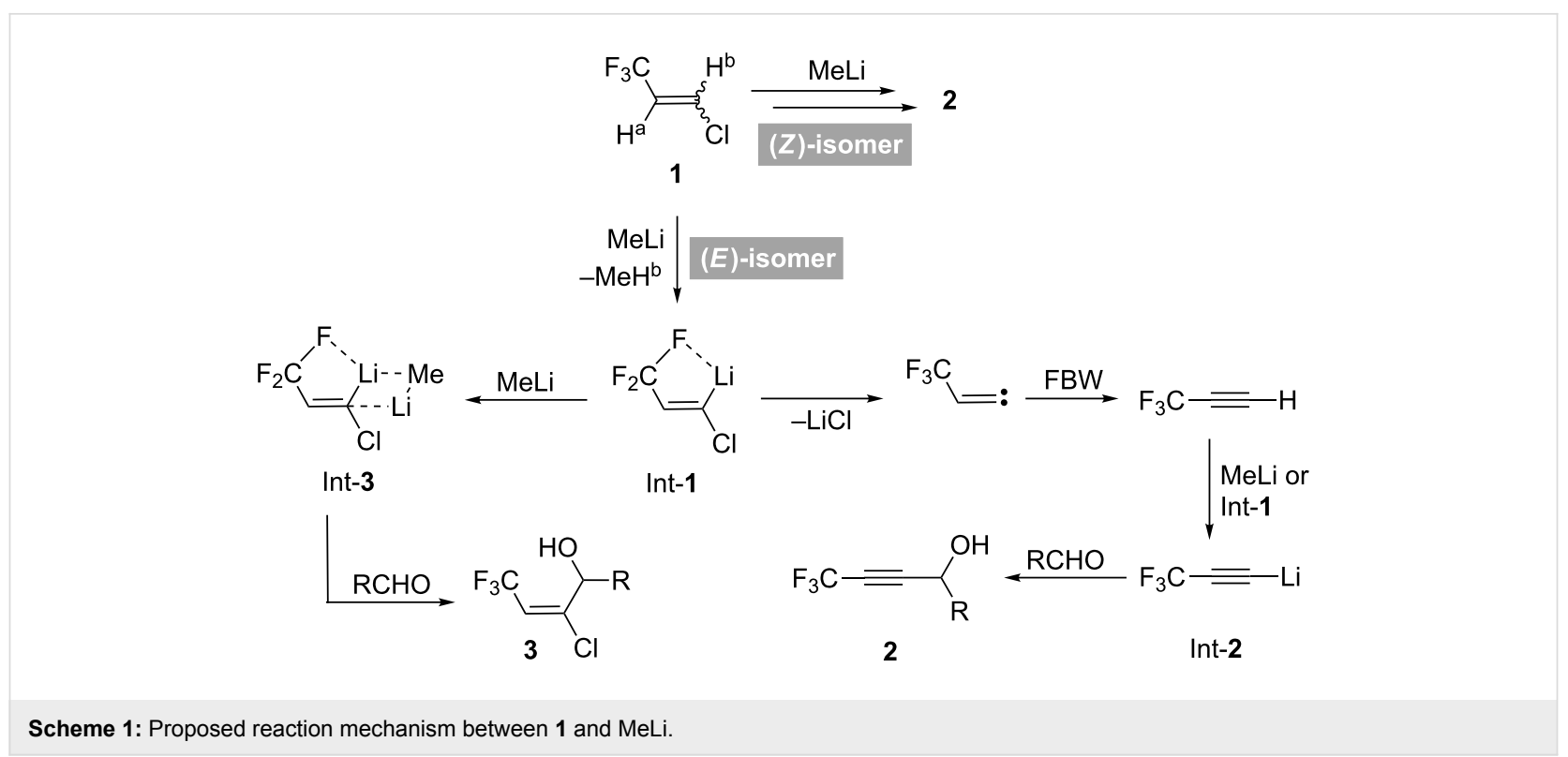

It was not only MeLi but also LDA which demonstrated this unique base-amount dependent product selectivity of $(E)-\mathbf{1}$ and this substrate was successfully converted to $\mathbf{2}$ or a mixture of $\mathbf{2 : 3}=25: 75$ by the action of 1.2 or 2.2 equiv of LDA, respectively. Although these phenomena are quite interesting, issues remain to be solved for complete mechanistic understanding of the process depicted in Scheme 1.

For clarification of the reactivity of $(E)-\mathbf{1}$ on deprotonation, enyne $\mathbf{4}$ was used as a model because, after trapping the vinylic anionic species by appropriate electrophiles, comparison of the yields of the resultant regioisomeric $\mathbf{5}$ and $\mathbf{6}$ would give us a hint for solving this puzzling question. Moreover, we also expected that such data as well as the additional deuterium trap experiment would offer deeper insight to the actual mechanism.

\section{Results and Discussion}

Investigation of reaction conditions was initially carried out in $\mathrm{Et}_{2} \mathrm{O}$. A complete recovery of $\mathbf{4}$ was observed irrespective of the base used (Table 1, entries 1 and 2).

Neither were 5a and 6a detected in THF when MeLi or $n$-BuLi were employed and this system produced only a complex mixture (Table 1, entries 3 and 4). A survey of bases established that, in spite of failures with $\mathrm{PhMgBr}$ and LHMDS, the use of LDA led to the formation of $5 \mathbf{a}$ and $6 \mathbf{a}$ in 24 and $6 \%$ yields, respectively, after trapping the resultant anionic intermediates by PhCHO (Table 1, entries 5 to 7). An increase in LDA concentration to 2 equiv improved the yield of product to $41 \%$ (5a) and $10 \%$ (6a), but additional LDA was not effective (Table 1 , entries 8 and 9). Subsequent to determining that LDA was the base of choice, a brief study of the effect of additives was performed. The addition of HMPA or DMPU was detrimental and no trace amount of $\mathbf{4}, \mathbf{5 a}$, nor $\mathbf{6 a}$ was detected (Table 1, entries 10 and 11). However, TMEDA affected this process to some extent (Table 1, entries 5 vs 12) [16-18], and the addition of 2 equiv each of LDA and TMEDA produced the regioisomeric 5a and 6a in better yields of $68 \%$ and $11 \%$, respectively (Table 1, entry 13). The recovery of $15 \%$ of the substrate 4 under these conditions prompted further raise in their amount to 3 equiv, but again, no significant improvement was noticed (Table 1, entries 13 vs 14). The effect of temperature on the reaction was crucial. Thus, efficient deprotonation was not occurred at $-100{ }^{\circ} \mathrm{C}$ (Table 1 , entry 15 ) with the consequence that decomposition of the vinylic anions at $-40{ }^{\circ} \mathrm{C}$ led to formation of different intermediates which would further consume LDA, leaving a larger amount of $\mathbf{4}$ unreacted (Table 1, entry 17). In conclusion, the reaction conditions in entry 13 in Table 1 were selected to be optimal.

With optimized conditions in hand, the scope and limitation of this procedure were investigated. A number of carbonyl compounds were employed as electrophiles for the anions generated from the enyne 4. Benzaldehydes with electron-donating (Table 2, entries 2 and 3) as well as -withdrawing (Table 2, entry 4) substituents at the para position were nicely accepted as electrophiles. The allylic alcohols $\mathbf{5}$ were formed as the major product without exception in a similar $5 /(5+6)$ ratio of $70-75 \%$ (Table 2, entries 1 to 5). An inseparable mixture of the compounds 5 and $\mathbf{6}$ was also synthesized from aliphatic aldehydes as shown in entries 5 and 6 in Table 2. Their proportion seemed to be affected by the bulky substituent and pivalaldehyde attained the higher ratio of $88 \%$. Although 5 and $\mathbf{6}$ were obtained in 50 to $70 \%$ combined yields by the reaction with 
Table 1: Investigation of reaction conditions.
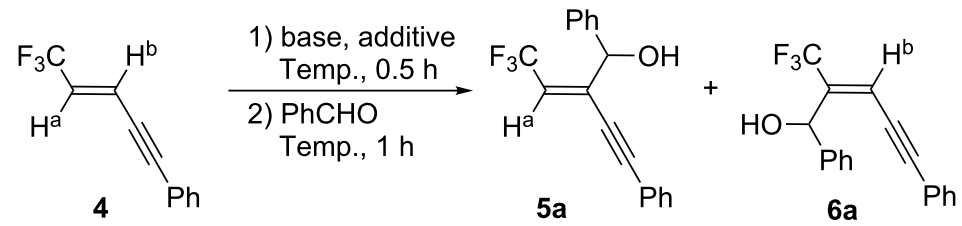

\begin{tabular}{|c|c|c|c|c|c|c|c|}
\hline \multirow[b]{2}{*}{ Entry } & \multirow[b]{2}{*}{ Solvent } & \multirow{2}{*}{$\begin{array}{l}\text { Base } \\
\text { (equiv) }\end{array}$} & \multirow{2}{*}{$\begin{array}{l}\text { Additive } \\
\text { (equiv) }\end{array}$} & \multirow{2}{*}{$\begin{array}{l}\text { Temp. } \\
\left({ }^{\circ} \mathrm{C}\right)\end{array}$} & \multicolumn{2}{|c|}{${ }^{19} \mathrm{~F}$ NMR Yield (\%) } & \multirow{2}{*}{$\begin{array}{l}\text { Recov. }^{2} \\
(\%)\end{array}$} \\
\hline & & & & & $5 a$ & $6 a$ & \\
\hline 1 & $\mathrm{Et}_{2} \mathrm{O}$ & $n$-BuLi (1.0) & - & -80 & 0 & 0 & 100 \\
\hline 2 & & $\operatorname{MeLi}(1.0)$ & - & -80 & 0 & 0 & 100 \\
\hline 3 & THF & $n$-BuLi (1.0) & - & -80 & 0 & 0 & 5 \\
\hline 4 & & MeLi (1.0) & - & -80 & 0 & 0 & 17 \\
\hline 5 & & $\operatorname{LDA}(1.0)$ & - & -80 & 24 & 6 & 20 \\
\hline 6 & & $\mathrm{PhMgBr}(1.0)$ & - & -80 & 0 & 0 & 17 \\
\hline 7 & & LHMDS (1.0) & - & -80 & 0 & 0 & 17 \\
\hline 8 & & $\operatorname{LDA}(2.0)$ & - & -80 & 41 & 10 & 15 \\
\hline 9 & & $\operatorname{LDA}(3.0)$ & - & -80 & 44 & 8 & 32 \\
\hline 10 & & $\operatorname{LDA}(1.0)$ & HMPA (1.0) & -80 & $-^{\mathrm{b}}$ & & \\
\hline 11 & & $\operatorname{LDA}(1.0)$ & DMPU (1.0) & -80 & $-{ }^{\mathrm{b}}$ & & \\
\hline 12 & & $\operatorname{LDA}(1.0)$ & TMEDA (1.0) & -80 & 34 & 2 & 11 \\
\hline 13 & & $\operatorname{LDA}(2.0)$ & TMEDA (2.0) & -80 & 68 & 11 & 15 \\
\hline 14 & & $\operatorname{LDA}(3.0)$ & TMEDA (3.0) & -80 & 64 & 19 & 14 \\
\hline 15 & & $\operatorname{LDA}(2.0)$ & TMEDA (2.0) & -100 & 19 & 5 & 76 \\
\hline 16 & & $\operatorname{LDA}(2.0)$ & TMEDA (2.0) & -60 & 50 & 17 & 1 \\
\hline 17 & & $\operatorname{LDA}(2.0)$ & TMEDA (2.0) & -40 & $-{ }^{b}$ & & 43 \\
\hline 18 & & $\operatorname{LDA}(2.0)$ & TMEDA (2.0) & $-80^{c}$ & 54 & 17 & 8 \\
\hline
\end{tabular}

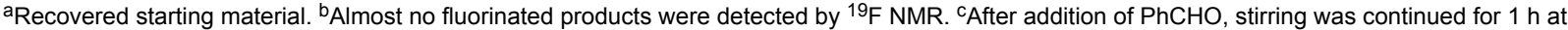
$-80^{\circ} \mathrm{C}$, followed by $3 \mathrm{~h}$ at $0{ }^{\circ} \mathrm{C}$.

Table 2: Scope and limitation of the present reactions.
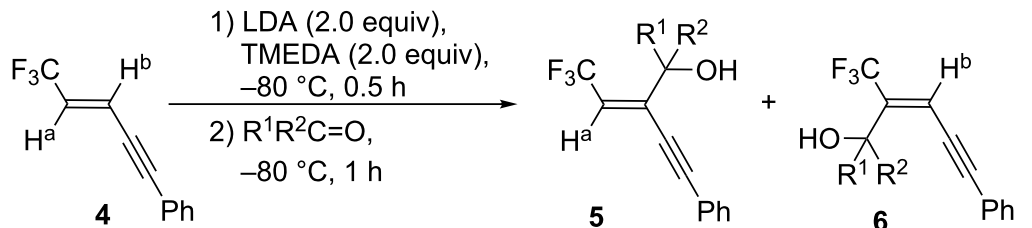

\begin{tabular}{|c|c|c|c|c|c|c|c|}
\hline \multirow[b]{2}{*}{ Entry } & \multirow[b]{2}{*}{$\mathrm{R}^{1}$} & \multirow[b]{2}{*}{$\mathrm{R}^{2}$} & \multirow[b]{2}{*}{ Product } & \multicolumn{2}{|c|}{ Isolated yield ${ }^{a}(\%)$} & \multirow{2}{*}{$\begin{array}{l}5 /(5+6)^{b} \\
(\%)\end{array}$} & \multirow{2}{*}{$\begin{array}{l}\text { Recov. }^{c} \\
(\%)\end{array}$} \\
\hline & & & & 5 & 6 & & \\
\hline 1 & $\mathrm{Ph}-$ & $\mathrm{H}$ & a & $50(65)$ & $21(25)$ & 72 & 15 \\
\hline 2 & $p-\mathrm{Me}-\mathrm{C}_{6} \mathrm{H}_{4-}$ & $\mathrm{H}$ & b & $49(52)$ & $17(17)$ & 75 & 18 \\
\hline 3 & $p-\mathrm{MeO}-\mathrm{C}_{6} \mathrm{H}_{4-}$ & $\mathrm{H}$ & C & $49(43)$ & $15(17)$ & 72 & 16 \\
\hline 4 & $p-\mathrm{F}_{3} \mathrm{C}-\mathrm{C}_{6} \mathrm{H}_{4^{-}}$ & $\mathrm{H}$ & d & $36(43)$ & $12(17)$ & 72 & 32 \\
\hline 5 & Et- & $\mathrm{H}$ & e & $47(57)$ & $16(19)$ & 75 & 26 \\
\hline 6 & $t$-Bu- & $\mathrm{H}$ & f & $54(59)$ & $10(8)$ & 88 & 23 \\
\hline 7 & $\mathrm{Ph}-$ & Me- & $\mathbf{g}$ & $(15)$ & (8) & 65 & 52 \\
\hline
\end{tabular}

an the parenthesis were shown the yields determined by ${ }^{19} \mathrm{~F} \mathrm{NMR}$. ${ }^{\mathrm{b}}$ These ratios were determined by ${ }^{19} \mathrm{~F}$ NMR for the crude materials. ${ }^{\mathrm{C}}$ Recovered starting material. 
aldehydes, lower reactivity was displayed by the less electrophilic and more hindered acetophenone. Products $5 \mathbf{g}$ and $\mathbf{6 g}$ were formed in $15 \%$ and $8 \%$ yields, respectively, while there was a $52 \%$ recovery of 4 under these conditions detected by ${ }^{19} \mathrm{~F}$ NMR (Table 2, entry 7).

Compounds 5 and $\mathbf{6}$ were readily characterized by ${ }^{19} \mathrm{~F}$ NMR spectra. The former material showed clear ${ }^{3} J$ couplings of 7 to $9 \mathrm{~Hz}$ between $\mathrm{F}$ and $\mathrm{H}^{\mathrm{a}}$, but with the latter ${ }^{4} J_{\mathrm{F}-\mathrm{Hb}}$ was usually not observed. Moreover, the fact that isolation of the furan 7a in $51 \%$ yield was realized by subjection of a 70:30 mixture of inseparable 5a and 6a to the already reported Pd-catalyzed cyclization conditions [19] suggested that the major isomer should be 5a, not 6a (Scheme 2). In the case of 5 and $\mathbf{6}$, electrophiles were incorporated without stereochemical contamination in all instances.

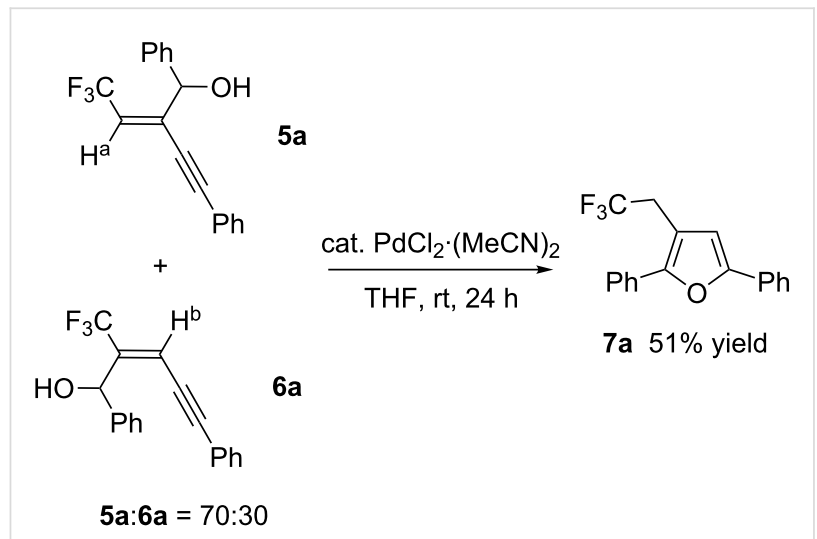

Scheme 2: Furan synthesis from a mixture of $\mathbf{5 a}$ and $\mathbf{6 a}$.

For obtaining further mechanistic proofs for the present reaction, we have planned to capture the intermediary anionic species with the aid of the usual deuteration technique. Thus, a large excess amount (26 equiv) of $\mathrm{CD}_{3} \mathrm{OD}$ was introduced to a solution containing the anionic species which was prepared from 4 by the standard conditions, which expected us to obtain a mixture of 4-d1 and 4-d2 or either of them predominantly (Scheme 3).
Observation of the well-resolved two sets of peaks was possible for the two vinylic protons $\mathrm{H}^{\mathrm{a}}$ and $\mathrm{H}^{\mathrm{b}}$ in the enyne 4 at $\delta 6.15$ $(\mathrm{qd}, J=6.6,15.9 \mathrm{~Hz})$ and $6.48(\mathrm{qd}, J=2.4,15.9 \mathrm{~Hz})$, respectively (Figure 1 and Supporting Information File 1).

On the other hand, relatively complex peaks were detected from the crude deuterated mixture due to incomplete quench of the reactive anionic species by $\mathrm{CD}_{3} \mathrm{OD}$, but new resonance peaks (indicated by $\boldsymbol{\Pi}$ and $\boldsymbol{\Lambda}$ ) undoubtedly appeared with overlapping the ones of the original $\mathrm{H}^{\mathrm{a}}(\star)$ and $\mathrm{H}^{\mathrm{b}}(\bullet)$. At the lower field (around $6.5 \mathrm{ppm}$ ) area, peaks indicated by $\boldsymbol{\Delta}$ are considered as a part of quartet with a coupling constant of $2.3 \mathrm{~Hz}$, which is close to the ${ }^{4} J_{\mathrm{H}-\mathrm{F}}$ coupling value of $\mathbf{4}$ shown above. Moreover, disappearance of the large ${ }^{3} J_{\mathrm{H}-\mathrm{H}}$ constant typical for $(E)$ alkenes suggested that a deuterium atom should be incorporated at the site where $\mathrm{H}^{\mathrm{a}}$ was originally situated and that 4-d2 was actually produced. It is also clear that the $\mathrm{H}^{\mathrm{a}}$ region also contains a couple of peaks ( $\mathbf{a})$ with the ${ }^{3} J_{\mathrm{H}-\mathrm{F}}$ coupling constant of $6.6 \mathrm{~Hz}$ basically identical to the one of 4 , which anticipated us the simultaneous formation of the regioisomeric 4-d1 on the basis of the similar consideration.

Thus, lithiation of 4 and the following quench with $\mathrm{CD}_{3} \mathrm{OD}$ furnished a mixture of 4-d1 and 4-d2, which directly proved that the both lithiated species $\mathbf{4 - L i 1}$ and $\mathbf{4 - L i 2}$ were actually generated (Scheme 4), although it is quite unfortunate not to be able to quantitatively discuss the proportion of 4-d1 to 4-d2. On the other hand, as apparent from Table 2, aldehydes preferentially yielded 5 with qualitatively better ratio of $5 / 6$ than the one of 4-d1/4-d2. Our computation of 4-Li1 and 4-Li2 by Gaussian 09W [20] using the B3LYP/6-31+G* level of theory uncovered that the former was energetically more favorable than the latter by 5.34 (3.67) kcal/mol under vacuum (in THF [21]), which would indicate that intramolecular $\mathrm{Li} \cdots \mathrm{F}$ chelation is contributed to the stability more significantly rather than the electron-withdrawing stabilization by the $\mathrm{CF}_{3}$ group. Thus, with this computational information in hand, the process shown in Scheme 4 would be elucidated as follows: deuteration would quickly occur to afford 4-d1 and 4-d2 whose proportion would reflect the ratio of 4-Li1 and 4-Li2. On the other hand, less

Scheme 3: Deuteration of anionic species from 4. 


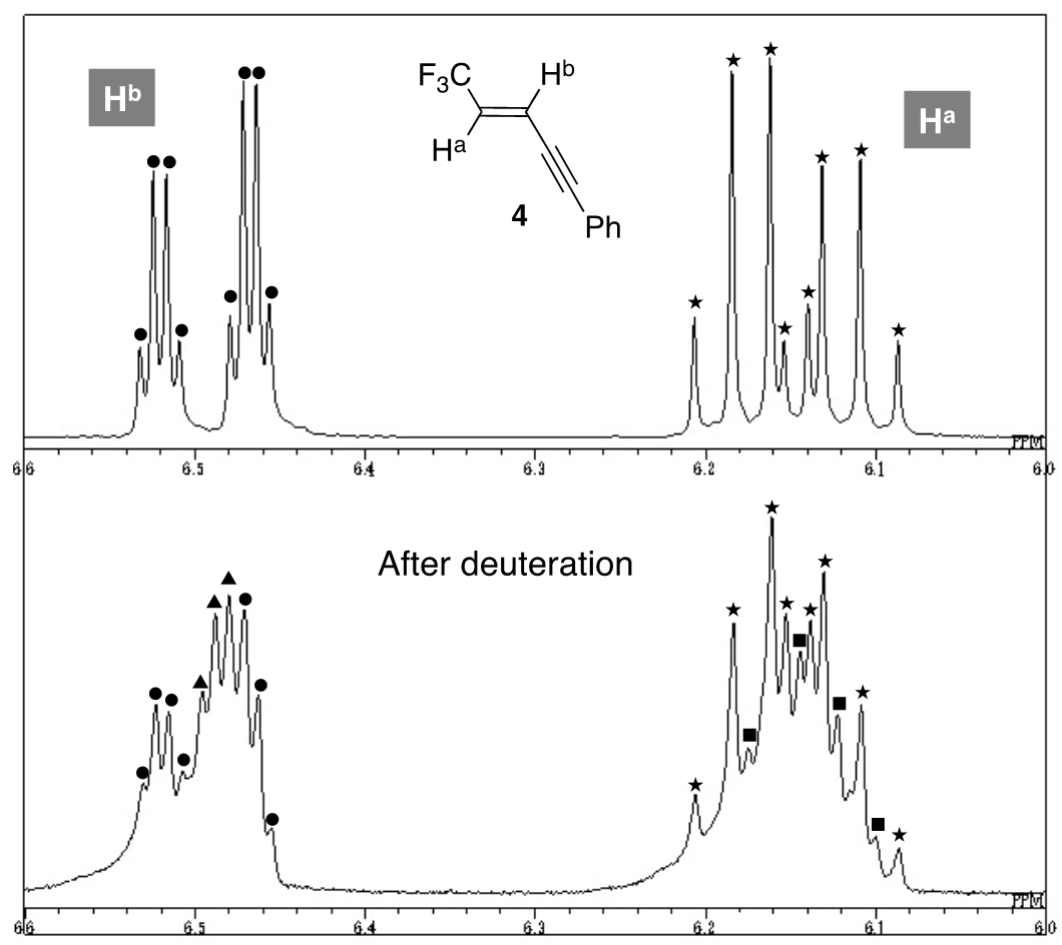

Figure 1: A part of ${ }^{1} \mathrm{H}$ NMR chart of 4 and its deuterated mixture.

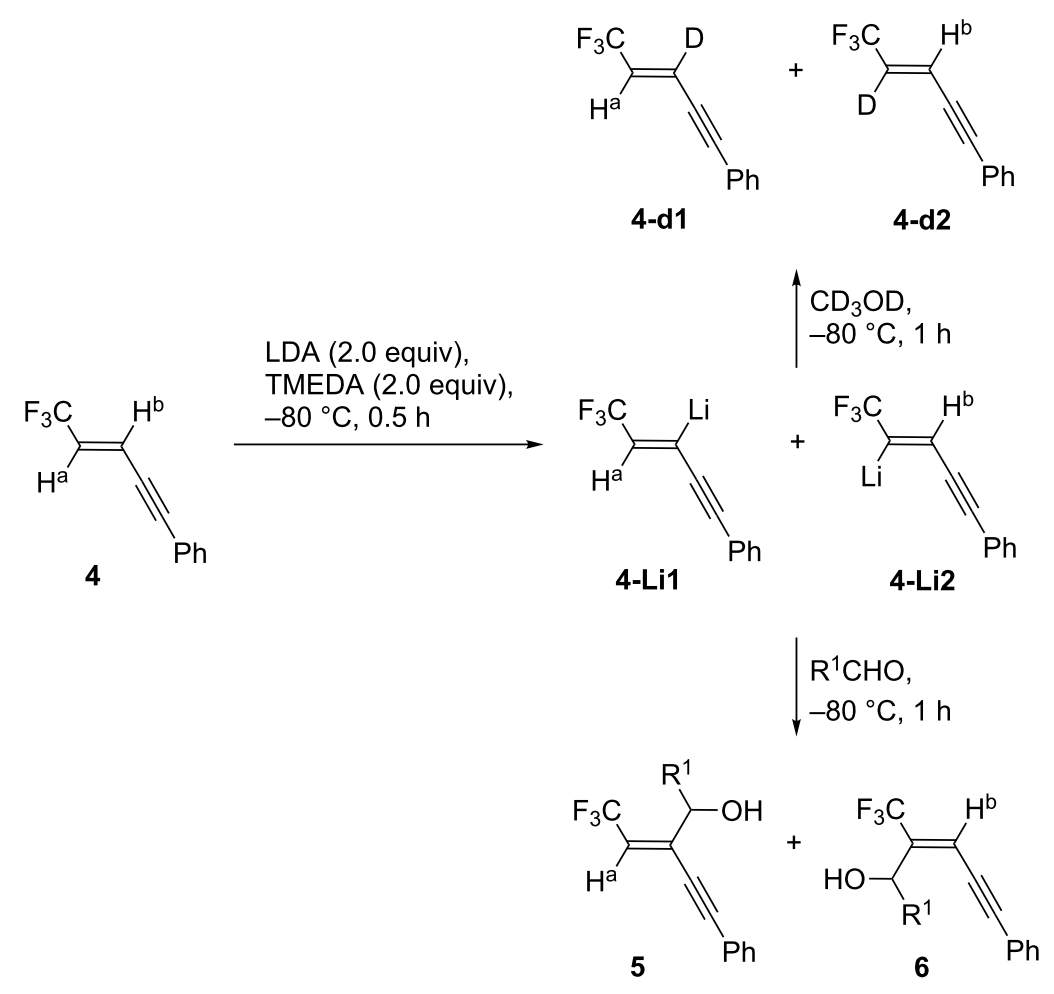

Scheme 4: Lithiation of 4 and the following electrophilic reactions. 
reactive aldehydes should be captured more slowly and the product preference of $\mathbf{5}$ to $\mathbf{6}$ would be kinetically determined by their activation energy difference with equilibration between these two lithiated species in the presence of such a proton source as $\mathrm{iPr}_{2} \mathrm{NH}[22]$.

This interpretation also led to the reconsideration of the proposed mechanism shown in Scheme 1. If deprotonation of both $\mathrm{H}^{\mathrm{a}}$ and $\mathrm{H}^{\mathrm{b}}$ in $(E)-\mathbf{1}$ was possible, lithiated species Int-4 and Int-1 was obtained, respectively (Scheme 5). Due to slow elimination of a $\mathrm{LiCl}$ molecule from Int-4 due to the cis relationship of $\mathrm{Li}$ and $\mathrm{Cl}$, Int-4 would act as a base to abstract a terminal proton of 3,3,3-trifluoropropyne via FBW rearrangement of Int1. The regenerated $(E)-\mathbf{1}$ would be converted to a mixture of Int-1 and Int-4 again to eventually yield the propargylic alco-

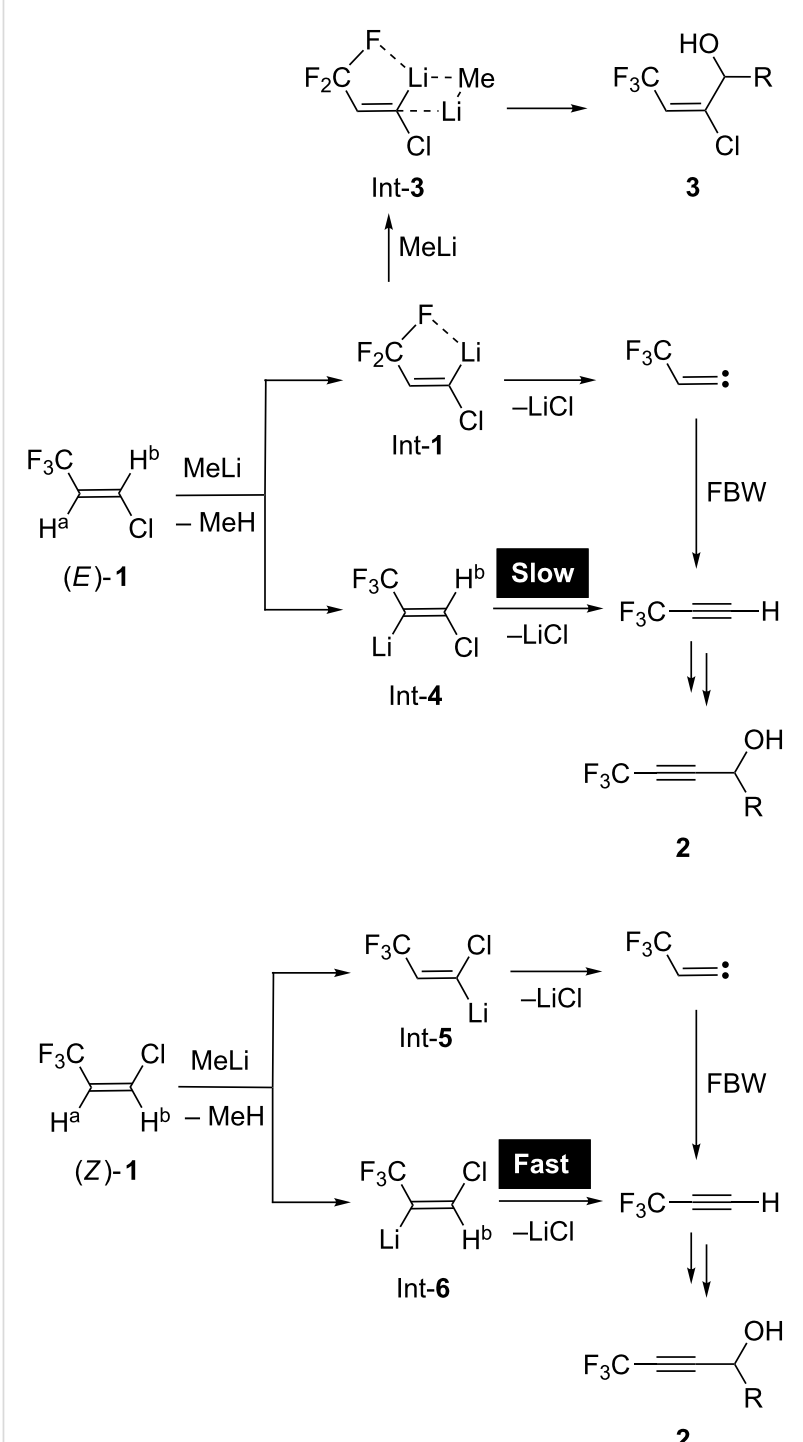

2

Scheme 5: Alternative reaction mechanism between 1 and MeLi. hols 2. However, a larger amount of MeLi would allow constructing the complex Int-3 presumably with possessing better stability and the allylic alcohols 3 were obtained. In the case of the stereoisomeric $(Z)-\mathbf{1}$, situation was totally different, and Int-5 without intramolecular chelation should accelerate the elimination of $\mathrm{LiCl}$ and the ideal trans disposition of $\mathrm{Li}$ and $\mathrm{Cl}$ in Int-6 also favored the route to trifluoropropyne, and as a result, propargylic alcohols 2 were selectively afforded.

\section{Conclusion}

By using the representative model substrate 4 , we have reached to a conclusion that its initial lithiation would occur at both vinylic sites and the following reactions with appropriate electrophiles would proceed under kinetic control where equilibration of the resultant lithiated species might be effective if the capture of electrophiles was slow. This important information allowed us to reconsider our previously proposed mechanism as shown in Scheme 5.

\section{Supporting Information}

\section{Supporting Information File 1 \\ Experimental. \\ [http://www.beilstein-journals.org/bjoc/content/ supplementary/1860-5397-9-256-S1.pdf]}

\section{References}

1. Miyagawa, A.; Naka, M.; Yamazaki, T.; Kawasaki-Takasuka, T. Eur. J. Org. Chem. 2009, 4395-4399. doi:10.1002/ejoc.200900370

2. Taguchi, T.; Tomizawa, G.; Nakajima, M.; Kobayashi, Y. Chem. Pharm. Bull. 1985, 33, 4077-4080. doi:10.1248/cpb.33.4077

3. Quan, H.-D.; Yang, H.-E.; Tamura, M.; Sekiya, A. J. Fluorine Chem. 2007, 128, 190-195. doi:10.1016/j.jfluchem.2006.12.004

4. Komata, T.; Akiba, S.; Hosoi, K.; Ogura, K. J. Fluorine Chem. 2008, 129, 35-39. doi:10.1016/j.jfluchem.2007.08.007

5. Shinohara, N.; Haga, J.; Yamazaki, T.; Kitazume, T.; Nakamura, S. J. Org. Chem. 1995, 60, 4363-4374. doi:10.1021/jo00119a013

6. Jahnke, E.; Tykwinski, R. R. Chem. Commun. 2010, 46, 3235-3249. doi:10.1039/c003170d

7. Knorr, R. Chem. Rev. 2004, 104, 3795-3850. doi:10.1021/cr030616h

8. Tajammal, S.; Tipping, A. E. J. Fluorine Chem. 1990, 47, 45-57. doi:10.1016/S0022-1139(00)80446-7

9. Mizutani, K.; Yamazaki, T.; Kitazume, T. J. Chem. Soc., Chem. Commun. 1995, 51-52. doi:10.1039/C39950000051

10. Katrizky, A. R.; Qi, M.; Wells, A. P. J. Fluorine Chem. 1996, 80, 145-147. doi:10.1016/S0022-1139(96)03494-X

11. Brisdon, A. K.; Crossley, I. R. Chem. Commun. 2002, 2420-2421. doi:10.1039/b207979h

12. Shimizu, M.; Higashi, M.; Takeda, Y.; Murai, M.; Jiang, G.; Asai, Y.; Nakao, Y.; Shirakawa, E.; Hiyama, T. Future Med. Chem. 2009, 1, 921-945. doi:10.4155/fmc.09.69

13. Eymery, F.; lorga, B.; Savignac, P. Synthesis 2000, 185-213. doi:10.1055/s-2000-6241 
14. Cristol, S. J.; Begoon, A.; Norris, W. P.; Ramey, P. S.

J. Am. Chem. Soc. 1954, 76, 4558-4561. doi:10.1021/ja01647a015

15. Behr, O. M.; Eglinton, G.; Lardy, I. A.; Raphael, R. A. J. Chem. Soc 1964, 1151-1154. doi:10.1039/jr9640001151

16. Kacem, Y.; Hassine, B. B. Tetrahedron Lett. 2013, 54, 4023-4025. doi:10.1016/j.tetlet.2013.05.082

17. Riggs, J. C.; Singh, K. J.; Yun, M.; Collum, D. B. J. Am. Chem. Soc. 2008, 130, 13709-13717. doi:10.1021/ja804087r

18. Grant, B. J.; Kramp, C. R.; Knight, J. D.; Meierhoefer, M. A.; Vella, J. H.; Sober, C. L.; Jones, S. S.; Metz, C. R.; Beam, C. F.; Pennington, W. T.; Vanderveer, D. G.; Camper, N. D.

J. Heterocycl. Chem. 2007, 44, 627-632. doi:10.1002/jhet.5570440318

19. Qing, F.-L.; Gao, W.-Z.; Ying, J. J. Org. Chem. 2000, 65, 2003-2006. doi:10.1021/jo991463u

20. Gaussian 09, Revision C.01; Gaussian, Inc.: Wallingford CT, 2009.

21. The integral equation formalism polarizable continuum model (IEF-PCM) was used for consideration of the solvent effect of THF.

22. Mongin, F.; Tognini, A.; Cottet, F.; Schlosser, M. Tetrahedron Lett. 1998, 39, 1749-1752. doi:10.1016/S0040-4039(98)00028-8

\section{License and Terms}

This is an Open Access article under the terms of the Creative Commons Attribution License

(http://creativecommons.org/licenses/by/2.0), which permits unrestricted use, distribution, and reproduction in any medium, provided the original work is properly cited.

The license is subject to the Beilstein Journal of Organic Chemistry terms and conditions:

(http://www.beilstein-journals.org/bjoc)

The definitive version of this article is the electronic one which can be found at: doi:10.3762/bjoc. 9.256 